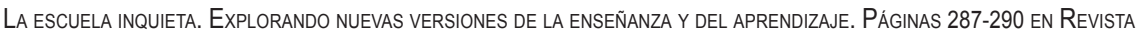
dE LA Escuela de CIENCIAS dE LA EdUCACIÓN, AÑo 11, NúMERO 10, ENERO A DICIEMBRE DE 2015. ISSN 1851-6297. ISSN EN LINEA 2362-3349.

\title{
LA ESCUELA INQUIETA. EXPLORANDO NUEVAS VERSIONES DE LA ENSEÑANZA Y DEL APRENDIZAJE
}

\author{
Por Mariana Saint Paul* \\ Universidad Nacional de Entre Ríos, Argentina. \\ saintpaulmariana@gmail.com
}

Recibido: 30/06/2014 Aceptado: 28/09/2014

Compiladora: Carina Rattero.

Editorial: Noveduc.

Año de edición: 2013.

\section{Resumen}

La presente reseña recorre los núcleos duros planteados en una compilación de Carina Rattero, pedagoga entrerriana, publicada en el año 2013. La misma reúne en dos partes IX capítulos que pretenden aproximar-nos al escenario educativo contemporáneo, no sólo desde sus problemas, sino además con producciones de maestros, pensadores e intelectuales que hacen foco en lo escolar desde adentro.

Palabras clave:

Enseñanza - Transmisión - Vínculo pedagógico - Experiencia - Pregunta.

\section{Abstract}

This review goes over the hard cores propose in a compilation of an "entrerriana" pedagogue, Carina Rattero published in 2013. The book consists in two parts with IX chapters that aim to bring us to the contemporary educational stage, not only from

Becaria de la Maestría en Filosofía de la Universidad Nacional de Quilmes. Prof. en Ciencias de la Educación (UNER). Docente en la Facultad de Ciencias de la Educación (UNER), en la Facultad de Humanidades, Artes y Ciencias Sociales de la UADER y Asesora Pedagógica en escuela secundaria de la ciudad de Paraná. 
Revista de la Escuela de Ciencias de la Educación, año 11, número 10, enero a diciembre de 2015. Páginas 287-290. ISSN 1851-6297. ISSN EN LINEA 2362-3349. LA ESCUELA INQUIETA. EXPLORANDO NUEVAS VERSIONES DE LA ENSEÑANZA Y DEL aprendizaje. Mariana Saint Paul

their problems, but also with writings by teachers, thinkers and intellectuals that focus on the school from the inside.

\section{Key words:}

Education - Transmission - Pedagogical link - Experience - Query.

\section{Reflexiones con el texto}

La presente reseña se ocupa de recuperar las principales temáticas del libro "La escuela inquieta. Explorando nuevas versiones de la enseñanza y del aprendizaje" compilado por Carina Rattero y con artículos de quien compila, y, Gabriel Brener, Víctor Debloc, Gabriel D’ Iorio, M. Beatriz Greco, M. Virginia Luna, Eduardo de la Vega y Mario Zerbino.

El mismo se organiza en dos partes. En la primera se trabaja sobre una escena escolar (una clase de Filosofía), desde la que los diferentes autores van a ir problematizando las figuras de autoridad y las "enseñanzas" a las que habilita la escuela actual.

En la segunda parte se van a trabajar cuestiones referidas al vínculo entre los docentes y los alumnos, y la posibilidad de habitar la escuela.

"Este libro se trama de miradas y lecturas (...)" (Rattero, 2013, p. 9), comienza diciendo la compiladora de La escuela Inquieta. Miradas sobre la actualidad escolar, lecturas profundas, sobre los componentes de esta realidad que nos acaricia y nos golpea a diario.

Entrando en la urdimbre, comprendiendo esta trama es que, a mi entender necesitamos situarnos, intentar constituir esa multi-referencialidad tan requerida en la esfera educativa.

Contextualizando las producciones reunidas en esta compilación nos ubicamos en los grandes cambios y transformaciones a los que asistimos desde el año 2006 hasta nuestros días, en términos normativos en educación. Aparentemente lo que los discursos pedagógicos dicen sobre la escuela no alcanza, no "llega", no problematiza a sus actores y sólo acumulamos pilas y pilas de nuevas problemáticas que impiden y obstaculizan, insisto, en lo discursivo, que la especificidad de lo escolar siga siendo la transmisión de conocimientos. Pero ¿Qué pasa en las escenas áulicas? ¿Qué acontece en el tiempo escolar?

Epocalmente estamos en una bisagra, es decir, los cambios legislativos que supone la sanción de la Ley de Educación Nacional y todas sus aplicaciones jurisdiccionales están transformando la lógica escolar. Otros tiempos y espacios habilitados para enseñar y para aprender, otras formas posibles para lo escolar empoderando las propuestas que desafían las estructuras curriculares, otros modos de entender el conocimiento, su producción y circulación. La evaluación, la obligatoriedad, la inclusión...Y las propias dinámicas institucionales que no logran detenerse y pensar hacia el interior, ya que las urgencias y las agendas impuestas desde el "afuera" regulan su funcionamiento. 
Revista de la Escuela de Ciencias de la Educación, año 11, número 10, enero a diciembre de 2015. Páginas 287-290. ISSN 1851-6297. ISSN EN LINEA 2362-3349. LA ESCUELA INQUIETA. EXPLORANDO NUEVAS VERSIONES DE LA ENSEÑANZA Y DEL aprendizaje. Mariana Saint Paul

En este marco, la complejidad de lo educativo nos obliga permanentemente a preguntarnos. Es casi una especificidad de quien se dedica, interesa o preocupa por la escuela el acto de preguntar. Este preguntar-nos se constituye al calor de múltiples no-saberes, de incertidumbres que van consolidando efectos sobre lo educativo. La pregunta va, de este modo, construyendo diversas figuras escolares, es decir, en la interpelación se van consolidando acciones, respuestas, silencios, etiquetas, prácticas y teorías.

Así La escuela inquieta trae en sus páginas más preguntas, y al calor de éstas se van anudando algunas posibles respuestas, que en tanto provisorias nos invitan y convocan al saber.

No vamos a escribir aquí las eventuales intencionalidades de los autores de los textos compilados en este libro, sino lo que su lectura provoca y habilita, en otras palabras, lo que nos interpela. Como dice M. Virginia Luna, una de las autoras, esta compilación rompe la lógica con la que venimos pensando y escribiendo sobre lo escolar (Rattero, 2013, p. 137). Este "romper" no se ubica ya en los márgenes, fronteras o suburbios de lo pensable, sino que atraviesa la cotidianidad de quienes habitamos las instituciones educativas, se impone en su agenda donándonos un espacio... convocándonos a una cita a la que no podemos faltar.

\section{Un recorrido por lo que inquieta a la escuela}

Los textos reunidos en la publicación motivo de esta reseña, van a centrar su atención en dos cuestiones (sus dos partes): Una orientada a decirconjuntamente sobre la relación, o no-relación, de saber y con el saber en una escena áulica, y otra que interroga las principales problemáticas enunciadas, es decir, puestas en palabras acerca de lo escolar.

La escuela inquieta pone de manifiesto, desde otro registro y otras voces, la incertidumbre que genera la metamorfosis de lo escolar.

Las preocupaciones desarrolladas en esta compilación se organizan en dos partes. La primera inquieta, la segunda desafía. Entre lo inquietante de la escena primera y lo desafiante de los tres últimos capítulos nos encontramos con un espacio, como ya se mencionó, que nos recibe para pensar conjuntamente: ¿Qué hacemos cuando no podemos dar clases? ¿Qué hacemos si podemos dar clases y los alumnos no aprenden? ¿Qué es la autoridad? ¿Cómo se construye? ¿Quién desea qué cosas en las escuelas? ¿Qué figura/s para qué mundo escolarizado? ¿Qué hacemos con el bolazo, el aburrimiento, la aparente apatía?

"Sabemos" que en las instituciones en general se va condensando lo social, su contexto, las redes relacionales de los sujetos que la habitan... Que esto va de lo macro a lo micro y viceversa y que son complejas, muy complejas... La institución escolar es así: ¿"Sabemos" algo sobre lo escolar? En la historia del 
Revista de la Escuela de Ciencias de la Educación, año 11, número 10, enero a diciembre de 2015. Páginas 287-290. ISSN 1851-6297. ISSN EN LINEA 2362-3349. LA ESCUELA INQUIETA. EXPLORANDO NUEVAS VERSIONES DE LA ENSENAANZA Y DEL aprendizaje. Mariana Saint Paul

pensamiento acumulamos tomos sobre las problemáticas pedagógicas, hablamos de problemas contemporáneos, de cómo las transformaciones mundiales impactan en los modelos educativos, añoramos lo viejo, lo criticamos por ser conservador... constantemente la vorágine cotidiana impone temas, problemas, demandas, respuestas, más, más y más... Exhaustos llegamos a los pasillos, a las aulas, a nuestras teclas, a enseñar, a aprender, a gestionar, a pensar, a escribir, a reflexionar... ¿Qué hacemos con la escuela? Entre las palabras agotamiento y transformación se hacen visibles todas estas cuestiones que inquietan a esta institución.

Dos figuras muy interesantes sobresalen en el libro, el animal racional (en la primera parte) y la cucaracha kafkiana (en la segunda). El "deber ser" como imperativo y el "sapere aude" como posibilidad.

El animal racional es la musa de la primera parte, desde allí los siguientes cinco capítulos problematizan diferentes aristas de una escena que molesta. Un profesor de filosofía, que pretende enseñar, un grupo pequeño de alumnos que manifiestan no querer aprender y una observadora aguda que perpleja y angustiada narra los vínculos que desata esa realidad. Una Rectora sin autoridad, y con mucho autoritarismo refleja el modo en que se gestiona la escuela y se contiene, silencia lo imprevisto, lo que se presenta intempestivo... y como tal nos descoloca, no sabemos qué hacer.

En este no saber aparecen, en la segunda parte del libro, tres capítulos en la imagen de un viaje, del que ya sabemos nunca volveremos del mismo modo. Con éste la figura kafkiana, la cucaracha, esa que el espejo nos devuelve distorsionada, otra vez incomodando, pero ahora con propuestas: Corrernos de ese lugar en el que erróneamente la escuela se posiciona, salirnos de esas ocupaciones tediosas que malgastan nuestras energías, resituarnos en lo posible, en lo pensable, habilitarnos al deseo de querer el límite, y, transgredir deseando de saber... Sí, es difícil la tarea de querer enseñar y de aprender a querer aprender: "(...) Deseo de marcharnos de donde ya estamos, de lo que ya tenemos, de lo que ya somos, el deseo de marcharnos de nosotros mismos..." (Rattero, 2013, p.128).

Justamente dar sentido a lo que parece no tenerlo es el objetivo central del libro. Este "dar" compromete a los actores escolares en la tarea de enseñar y de aprender, garantizando un derecho y concertando proyectos de vida que resitúen al conocimiento como meta, más allá de las viejas promesas de la escuela moderna.

\section{Referencias Bibliográficas}

- $\quad$ Rattero, C. (Comp.). (2013). La escuela inquieta. Explorando nuevas versiones de la enseñanza y del aprendizaje. Buenos Aires: Noveduc. 